\title{
A new ASAP Scoring System and Risk Table to predict second prostate biopsy outcomes
}

Ediz Caner ${ }^{1}$, Akan Serkan ${ }^{1}$, Kaya Neslihan², Ihvan Aysenur ${ }^{3}$

${ }^{1}$ Department of Urology, Sultan Abdulhamid Han Education and Research Hospital, Istanbul, Turkey

2Department of Pathology, Sultan Abdulhamid Han Education and Research Hospital, Istanbul, Turkey

${ }^{3}$ Department of Pathology, Umraniye Education and Research Hospital, Istanbul, Turkey

Submitted: 26 September 2020; Accepted: 18 December 2020 Online publication: 15 October 2021

Arch Med Sci

DOI: https://doi.org/10.5114/aoms/131789

Copyright @ 2021 Termedia \& Banach

\section{Abstract}

Introduction: This study aimed to discuss the necessity of a second prostate biopsy in patients with atypical small acinar proliferation (ASAP) and to develop a scoring system and risk table to be used as new criteria for a second biopsy.

Material and methods: The study reviewed the data of 2,845 patients who underwent transrectal ultrasonography-guided prostate biopsy in the period between January 2008 and May 2019. A total of 128 patients with ASAP were included in the study. The tPSA, FPSA, f/tPSA, and PSA-density levels before the first and second biopsies and changes in the measured levels between the values obtained before the first and the second biopsies were recorded. The ASAP Scoring System and Risk Table (ASS-RT) was evaluated before the second biopsy.

Results: The mean age of 128 patients with ASAP was $62.9 \pm 7.8$ years. The ASS-RT scores of prostate cancer patients were significantly higher compared to patients without prostate cancer $(p=0.001)$. In the ROC curve analysis of ASS-RT, the area under the curve was 0.804 and the standard error was 0.04 . The area under the ROC curve was significantly higher than 0.5 ( $p=0.001)$. The cut-off point of ASS-RT scores in diagnosing cancer was $\geq 7$ with $60.8 \%$ sensitivity and $80.5 \%$ specificity.

Conclusions: The cut-off value of 7 determined for the ASS-RT score in this study suggests that patients with ASS-RT scores of $\geq 7$ should undergo a second prostate biopsy. We think that there may be no need for a second biopsy if the ASS-RT score is $<7$, especially for low-risk patients.

Key words: prostate-specific antigen, prostate biopsy, prostate cancer, atypical small acinar proliferation, ASAP Scoring System and Risk Table.

\section{Introduction}

Prostate cancer ( $\mathrm{PCa}$ ) is the most commonly diagnosed malignancy, excluding skin cancer, in men older than 70 years [1]. Prostate core needle biopsy (PCNB) is a gold standard test to diagnose PCa. Atypical small acinar proliferation (ASAP) was first described by Bostwick et al. [2] as foci of small acinar structures $(<0.4 \mathrm{~mm})$ formed by atypical epithelial cells which were diagnosed on PCNB. ASAP is diagnosed in $5 \%$ of all prostate biopsies $[3,4]$ and considered a precancerous lesion of the prostate

\author{
Corresponding author: \\ Ediz Caner MD \\ Department of Urology \\ Sultan Abdulhamid \\ Han Education and \\ Research Hospital \\ Istanbul, Turkey \\ Tibbiye Sok. \\ Selimiye Mah. \\ Uskudar/Istanbul \\ 34668 \\ Phone: +90 5335805080 \\ Fax: +90 2165422020 \\ E-mail: drcanerediz@gmail. \\ com
}


$[5,6]$. A second prostate biopsy is routinely recommended by the current National Comprehensive Cancer Network (NCCN) and European Association of Urology (EAU) guidelines $[7,8]$ because of the $30-40 \%$ PCa risk in patients who had ASAP on the initial biopsy $[9,10]$.

Morbidity associated with PCNB is a problem for both patients and clinicians [11-13]. Some patients wish to delay a second biopsy as much as possible. Furthermore, a transrectal ultrasonography (TRUS)-guided prostate biopsy is a high-cost procedure [14]. Besides the morbidity and high costs, the results obtained through a TRUS-guided prostate biopsy do not always show a clinically significant or high-risk PCa [15]. Therefore, performing a second prostate biopsy has been a controversial topic for years.

In this study, we aimed to discuss the requirement to perform second biopsies routinely in patients with ASAP and to determine criteria for identifying patients who should absolutely undergo a second biopsy. We present a scoring system and a risk table that may offer guidance on whether a second prostate biopsy should be performed.

\section{Material and methods}

This retrospective study was conducted in accordance with the principles of the World Medical Association Declaration of Helsinki - Ethical

Table I. ASAP Scoring System and Risk Table for patients with ASAP

\begin{tabular}{|lc|}
\hline \multicolumn{1}{|l|}{ Variable } & Points \\
\hline tPSA: & 1 \\
\hline$<4$ & 2 \\
\hline $4-10$ & 3 \\
\hline f/tPSA: & 3 \\
\hline$<0.15$ & 2 \\
\hline $0.15-0.25$ & 1 \\
\hline$>0.25$ & 1 \\
\hline PSA-D: & 2 \\
\hline$<0.08$ & 3 \\
\hline $0.08-0.129$ & 4 \\
\hline $0.13-0.15$ & $3-11$ \\
\hline$>0.15$ & $3-5$ \\
\hline tPSA: & $0-8$ \\
\hline Decreased (-) & 11 \\
\hline Increased (+) & \\
\hline Total score: & \\
\hline Low risk & \\
\hline High risk & \\
\hline
\end{tabular}

Principles for Medical Research Involving Human Subjects.

\section{Patient population}

A TRUS-guided prostate biopsy was performed in 2,845 cases due to elevated PSA levels and/or significant digital rectal examination (DRE) findings in our clinic in the period between January 2008 and May 2019. ASAP was found in 238 out of 2,295 prostate biopsy patients. Of these 238 patients, 128 with available data were included in the study.

\section{Inclusion and exclusion criteria}

Patients who had elevated prostate-specific antigen (PSA) levels and/or abnormal findings in a digital rectal examination were included in the study. Patients with urinary tract infections, coagulopathies, a history of surgery in the past year, or patients who received $5 \alpha$-reductase inhibitors as monotherapy or combination therapy, or patients with inadequate data were excluded from the study.

\section{Study design}

Patients' medical records were retrospectively reviewed. Patients' age, prostate volumes, total PSA (tPSA) and free PSA (fPSA) levels, the ratio of fPSA to tPSA ( $f /$ tPSA), and PSA-density (PSA-D) $(\mathrm{ml})$ levels were evaluated. Additionally, PSA velocity (PSA) was calculated for PSA types (tPSA, fPSA, f/tPSA and PSA-D $)$ as the difference in the measured levels between the values obtained before the first and the second biopsies.

\section{ASAP Scoring System and Risk Table (ASS-RT)}

Patients were divided into two groups according to the results of the second prostate biopsies. Group I included patients with benign prostate pathology (prostatitis or benign prostate hyperplasia) and group II included patients with PCa diagnosed on the second prostate biopsy. We designed a scoring system and a risk table to evaluate patients with ASAP before the repeat biopsy (Table I).

Four parameters, which would be scored from 0 to 3 or 4, were selected to be used in the scoring system and the risk table. tPSA levels were was scored from 1 to 3 points according to the values of $0-<4 \mathrm{ng} / \mathrm{dl}$, $4-10 \mathrm{ng} / \mathrm{dl}$, and $>10 \mathrm{ng} / \mathrm{dl}$, respectively. f/tPSA was scored from 1 to 3 points according to the values of $<0.15,0.15-0.25$, and $>0.25 \%$, respectively. PSA-D was scored from 1 to 4 points according to the levels of $<0.08,0.08$ $0.129,0.13-0.15$, and $>0.15 \mathrm{ng} / \mathrm{dl} / \mathrm{ml}$, respectively. PSA was scored 0 or 1 points according to 
the decrease or increase in the levels of TPSA before the second prostate biopsy. The total ASS-RT score that could be obtained ranged from 3 to 11 points. Finally, subsequent to all assessments, the patients included in the study were categorized according to their total scores as low (3-5), intermediate (6-8), or high-risk (9-11) patients.

\section{TRUS-guided prostate biopsy procedure}

Oral administration of $500 \mathrm{mg}$ levofloxacin and $400 \mathrm{mg}$ etodolac was started one day before the procedure and continued after the biopsy. On the day of the biopsy, a rectal enema $(250 \mathrm{ml})$ was performed before the biopsy. The biopsy was performed while the patient was in the left lateral position with the thighs flexed. The procedure was performed under the guidance of an ultrasound device with a $7.5 \mathrm{MHz}$ biplanar probe.

The biopsy was performed under outpatient clinic conditions in a room equipped with all material necessary for potential emergency intervention. Sedation or anesthesia was not administered. Periprostatic nerve blockade was performed $10 \mathrm{~min}$ before the procedure in addition to the perianal and intrarectal administration of lidocaine gel. Injections were delivered through the prostate-seminal vesicle angle on each side, using $5 \mathrm{ml}$ of $2 \%$ lidocaine. Biopsies were performed by more than one experienced urologist. Standard 12 or 10 core prostate biopsies were performed in initial biopsy procedures. The samples were collected from both lateral and medial aspects and from the base, apex, and medial surfaces on the right and left sides of the prostatic peripheral zone. A second prostate biopsy was performed within 3 to 6 months after the initial biopsy. The number of core samples taken at the second biopsy was 16 or 18 .

\section{Data analysis}

Data were analyzed using SPSS Statistics 22.0 software (SPSS Inc., Chicago, IL, USA) and Microsoft Excel. The data were tested for normality by the Shapiro-Wilk test. Normally distributed descriptive data were presented as mean and standard deviation. Otherwise, data were presented as median and minimum-maximum values. Based on the normal or non-normal distribution of the data, Student's $t$ test or the Mann-Whitney $U$ test was used to compare the first and second biopsy results. Receiver operating characteristic (ROC) curves were used to quantify the predictive accuracy of the results. Two-tailed levels of $p<0.05$ were considered statistically significant.

\section{Results}

The mean age of the patients with ASAP was $62.9 \pm 7.8$ years $(40-78)$. In the first prostate bi- opsy, the mean tPSA level, fPSA level, f/tPSA ratio, and PSA-D level were $8.63 \mathrm{ng} / \mathrm{ml}(0.9-32.5)$, $1.59 \mathrm{ng} / \mathrm{ml}$ (0.0017-8.9), 0.19 (0.0014-0.79), and $0.19 \mathrm{ng} / \mathrm{ml} / \mathrm{cc}(0.01-0.98)$, respectively. The second prostate biopsy results were reported as benign prostate pathology for 77 (60.2\%) patients and PCa for 51 (39.8\%) patients (ISUP Grade Group I: 36, ISUP Grade Group II: 10, and ISUP Grade Group IV: 5 patients). The mean prostate volumes in study groups I (patients with benign prostate pathology) and II (patients with PCa) were $58.96 \pm 30.66 \mathrm{ml}$ and $47.71 \pm 25.44 \mathrm{ml}$, respectively. The difference in the prostate volumes between the study groups I and II was significant $(p<0.037)$.

According to the first biopsy results of patients with PCa, tPSA levels increased before the second prostate biopsy. However, tPSA levels were found to have decreased in patients with benign prostate pathology. The difference in the tPSA levels between the patients with PCa and benign prostate pathology was significant ( $p=$ 0.001). The increase in fPSA levels before the second prostate biopsy compared to the first biopsy results was significantly smaller in $\mathrm{PCa}$ compared to patients with benign prostate pathology $(p=0.002)$. The $\mathrm{f} / \mathrm{tPSA}$ ratio decreased in group II before the second prostate biopsy but it increased in patients with benign prostate pathology with a significant difference $(p=0.001)$. In group II, PSA-D levels increased before the second prostate biopsy while they decreased in patients with benign prostate pathology and this difference was significant ( $p=0.001$ ) (Table II). Changes in the levels of the "PSA types" before the second prostate biopsy and respective statistical analysis results between the two groups are summarized in Table III. ASS-RT scores of the patients with PCa were significantly higher than those of the patients with benign prostate pathology $(p=0.001)$.

The ROC curve of ASS-RT scores was evaluated in making the diagnosis of PCa. The area under the curve was 0.804 and the standard error was 0.04 . The area under the ROC curve was significantly higher than $0.5(p=0.001 ; p<0.05)$. The cut-off point for the ASS-RT score in diagnosing $P C a$ was $\geq 7$. The sensitivity and specificity of the cut-off value were $60.8 \%$ and $80.5 \%$, respectively (Figure 1).

The ROC curve of tPSA was evaluated in making a diagnosis of PCa. The area under the curve was 0.790 and the standard error was 0.04. The area under the ROC curve was significantly higher than 0.5 ( $p=0.001 ; p<0.05)$. The determined cut-off point for TPSA in diagnosing $\mathrm{PC}$ a was $>0.4$. The sensitivity and specificity of the cut-off value were $88.2 \%$ and $71.4 \%$, respectively (Figure 1 ). 
Table II. The results before the first and second biopsies and the change in measured levels between the first and second prostate biopsies

\begin{tabular}{|c|c|c|c|c|}
\hline Variable & $\begin{array}{c}\text { PSA } \\
\text { types }\end{array}$ & $\begin{array}{c}\text { First biopsy } \\
\text { Mean } \pm \text { SD (median) }\end{array}$ & $\begin{array}{c}\text { Second biopsy } \\
\text { Mean } \pm \text { SD (median) }\end{array}$ & $P$-value \\
\hline \multirow{4}{*}{$\begin{array}{l}\text { ASAP to benign pathology } \\
(n=77)\end{array}$} & tPSA & $8.62 \pm 6.2(6.3)$ & $6 \pm 4.22(5,1)$ & 0.003 \\
\hline & fPSA & $1.7 \pm 1.25(1.3)$ & $1.22 \pm 0.79(1.1)$ & $>0.05$ \\
\hline & $f / t P S A$ & $0.21 \pm 0.08(0.2)$ & $0.23 \pm 0.1(0.2)$ & 0.001 \\
\hline & PSA-D & $0.18 \pm 0.17(0.14)$ & $0.13 \pm 0.12(0.1)$ & 0.001 \\
\hline \multirow[t]{4}{*}{ ASAP to PCa $(n=51)$} & tPSA & $8.6 \pm 6.68(6.2)$ & $8.85 \pm 6.68(6.5)$ & 0.003 \\
\hline & fPSA & $1.42 \pm 1.52(1)$ & $1.19 \pm 0.95(0.9)$ & $>0.05$ \\
\hline & f/tPSA & $0.18 \pm 0.13(0.2)$ & $0.15 \pm 0.08(0.1)$ & 0.001 \\
\hline & PSA-D & $0.21 \pm 0.16(0,17)$ & $0.22 \pm 0.16(0.2)$ & 0.001 \\
\hline
\end{tabular}

ASAP - atypical small acinar proliferation, PCa - prostate cancer, tPSA - total prostate-specific antigen, fPSA - free prostate-specific antigen, f/tPSA - free to total prostate-specific antigen ratio, PSA-D - prostate-specific antigen density.

Table III. Changes in pre-biopsy levels of the "PSA types" between the first and second prostate biopsies and comparison between the two groups

\begin{tabular}{|lccc|}
\hline Variables & $\begin{array}{c}\text { Group I }(n=77) \\
\text { Mean } \pm \text { SD (median) }\end{array}$ & $\begin{array}{c}\text { Group II }(n=51) \\
\text { Mean } \pm S D \text { (median) }\end{array}$ & $P$-value \\
\hline tPSAv & $-2.61 \pm 4.79(-1.3)$ & $0.29 \pm 2.69(0.1)$ & $0.001^{*}$ \\
\hline fPSAv & $0.48 \pm 1.13(0.2)$ & $0.24 \pm 1.01(0)$ & $0.002^{*}$ \\
\hline f/tPSAv & $0.02 \pm 0.09(0)$ & $-0.03 \pm 0.1(0)$ & $0.001^{*}$ \\
\hline PSA-Dv & $-0.05 \pm 0.18(0)$ & $0.01 \pm 0.09(0)$ & $0.001^{*}$ \\
\hline
\end{tabular}

Mann-Whitney $U$ Test, ${ }^{*} p<0.05$. ASAP - atypical small acinar proliferation, $P C a$ - prostate cancer, tPSA - total prostate-specific antigen velocity, $f P S A_{v}$ - free prostate-specific antigen velocity, f/tPSA - free to total prostate-specific antigen ratio velocity, PSA-D - prostatespecific antigen density velocity.

The ROC curve of PPSA was evaluated in diagnosing PCa. The area under the curve was 0.664 and the standard error was 0.05 . The area under the ROC curve was significantly higher than 0.5 $(p=0.001 ; p<0.05)$. The determined cut-off point for PPSA in diagnosing PCa was $\leq 0.12$. The sensitivity and specificity of the cut-off value were $78.4 \%$ and $62.3 \%$, respectively (Figure 1 ).

The ROC curve of f/tPSA was evaluated in diagnosing PCa. The area under the curve was 0.696 and the standard error was 0.05. The area under the ROC curve was significantly higher than 0.5 $(p=0.001 ; p<0.05)$. The determined cut-off point for $f / t P S A_{v}$ in diagnosing $P C a$ was $\leq 0.02$. The sensitivity and specificity of the cut-off value were $92.2 \%$ and $40.3 \%$, respectively (Figure 1 ).

The ROC curve of PSA-D was evaluated in diagnosing PCa. The area under the curve was 0.745 and standard error was 0.04 . The area under the ROC curve was significantly higher than 0.5 ( $p=$ $0.001 ; p<0.05)$. The determined cut-off point for $P S A-D_{v}$ in diagnosing PCa was $>0.02$. The sensitivity and specificity of the cut-off value were $88.2 \%$ and $58.4 \%$, respectively (Figure 1 ).

\section{Discussion}

Atypical small acinar proliferation is a pathologic entity that should be re-evaluated on a sec- ond biopsy when small foci cannot be clearly defined histopathologically and when a differential diagnosis of PCa cannot be definitively made. The detection rate of ASAP in our biopsy cohort was $11.28 \%$. The rate of detecting ASAP has increased especially over the past few years. We think that the increased rate of detecting ASAP has resulted from the recently accepted reduction of the tPSA threshold value from 4 to $2.5 \mathrm{ng} / \mathrm{ml}$. Second biopsy rates are reported to vary in the range of $47-63 \%$ in the literature [16]. Our re-biopsy rate, which was $53.78 \%$, was in line with the literature. Here, the question to answer is "why do patients wish to avoid undergoing a second biopsy?". Then, the underlying reasons should be investigated further. Indeed, because of the apparent psychological or physical difficulties that would potentially be inflicted by the biopsy procedure, it is difficult to convince patients to undergo a second biopsy. Furthermore, such a low rate reflects the public's approach to a prostate biopsy, especially in Muslim countries. Therefore, the necessity of a second prostate biopsy is always scrutinized. Moreover, the decision to perform a second biopsy should be carefully made because a second biopsy will be associated with additional costs and the risk of morbidity.

PCa occurred in $39.84 \%$ of our patients with ASAP who underwent a second prostate biopsy. In 
A

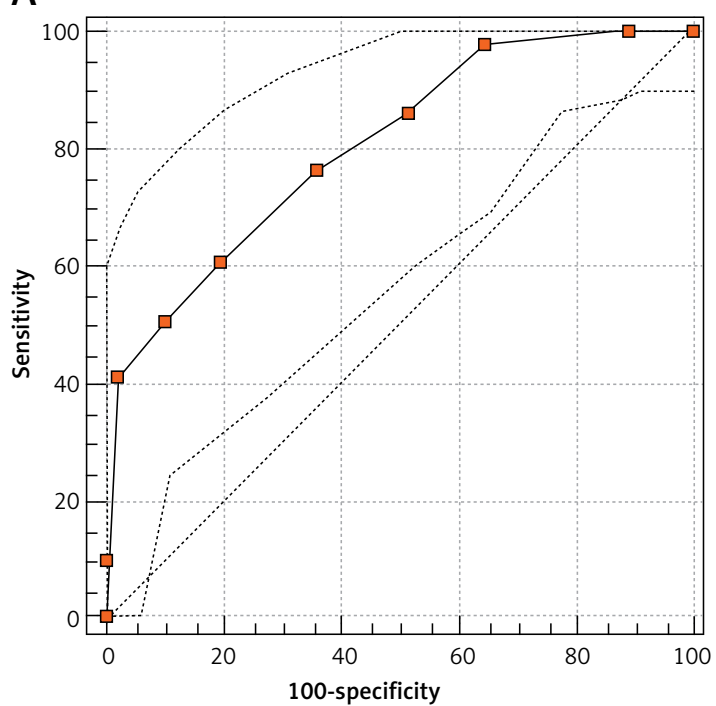

C

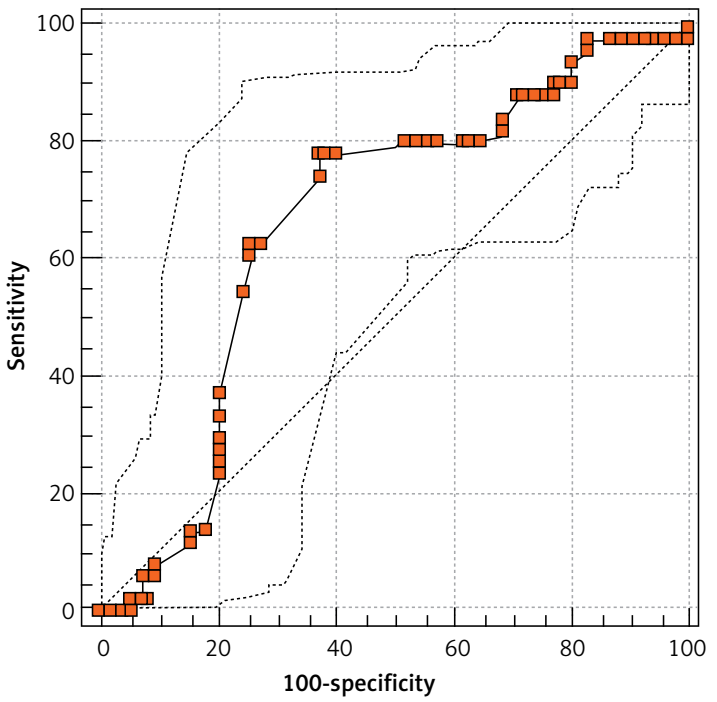

E

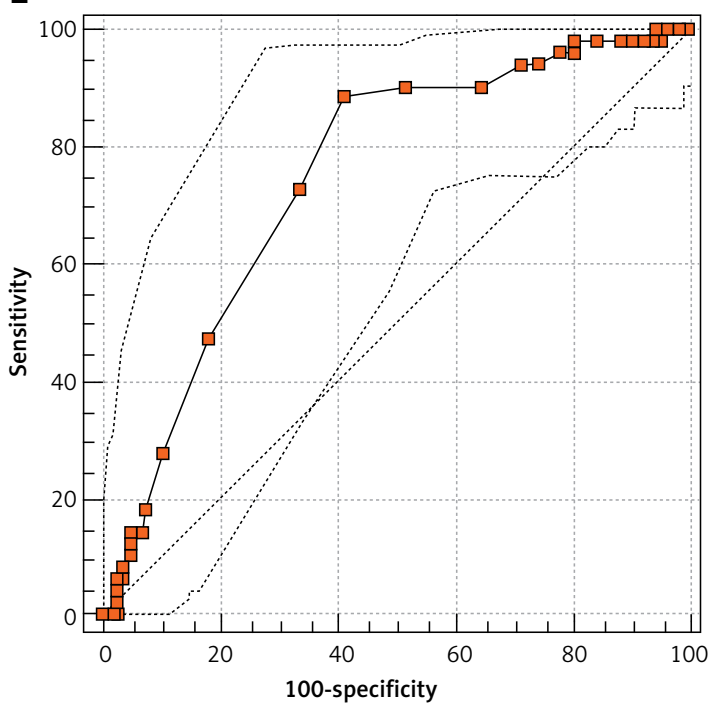

B

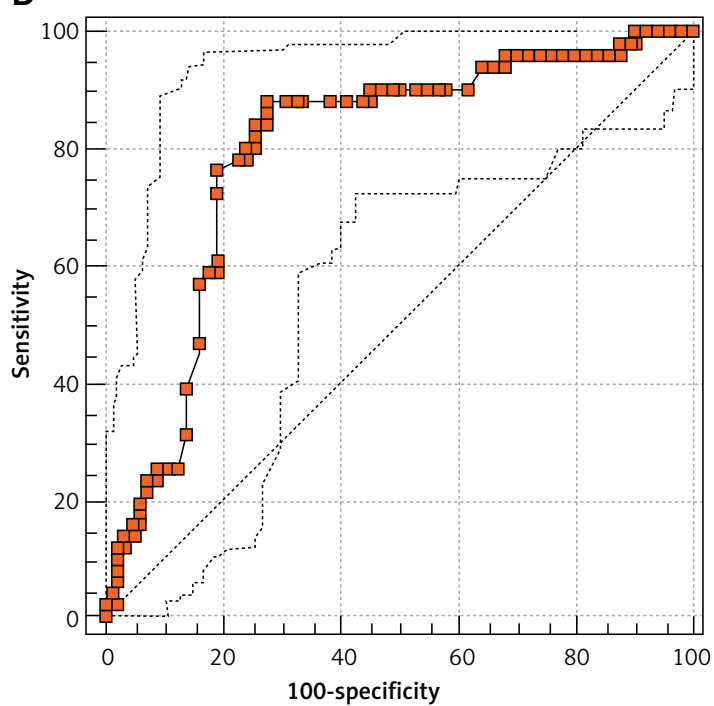

D

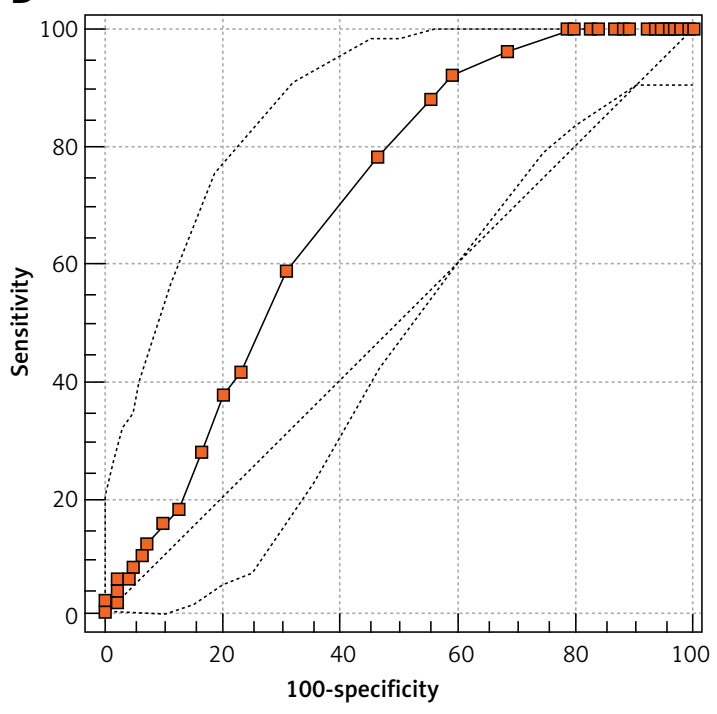

Figure 1. ROC curve graphs of GATA Scoring System and Risk Tables score (A), tPSA (B), fPSA (C), f/tPSA $($ D) and PSA-D $(E)$ for ASAP Scoring System and Risk Tables score 
Table IV. Values of "PSA types" before the first and second prostate biopsies and by the risk groups

\begin{tabular}{|lcccc|}
\hline Variables & & $\begin{array}{c}\text { Low risk }(n=44) \\
\text { Median }(\text { min.-max. })\end{array}$ & $\begin{array}{c}\text { Intermediate risk }(n=50) \\
\text { Median }(\text { min.-max })\end{array}$ & $\begin{array}{c}\text { High risk }(n=34) \\
\text { Median (min.-max) }\end{array}$ \\
\hline $\begin{array}{l}\text { Before } \\
\text { the first } \\
\text { prostate } \\
\text { biopsy }\end{array}$ & tPSA & $6.07(0.9-19.50)$ & $9.09(2.29-31.00)$ & $11.17(3.00-32.50)$ \\
\cline { 2 - 5 } & fPSA & $1.37(0.20-4.50)$ & $1.82(0.38-8.90)$ & $1.51(0.001-6.10)$ \\
\cline { 2 - 5 } & f/tPSA & $0.22(0.08-0.38)$ & $0.20(0.03-0.62)$ & $0.15(0.001-0.79)$ \\
\hline $\begin{array}{l}\text { Before the } \\
\text { second } \\
\text { prostate } \\
\text { biopsy }\end{array}$ & PSA-D & $0.12(0.01-0.98)$ & $0.19(0.05-0.70)$ & $0.28(0.06-0.77)$ \\
\cline { 2 - 5 } & tPSA & $4.1(0.3-9.90)$ & $6.32(2.08-16.75)$ & $12.25(4.32-32.00)$ \\
\cline { 2 - 5 } & fPSA & $1.05(0.05-3.80)$ & $1.18(0.30-3.40)$ & $1.45(0.20-4.50)$ \\
\hline & f/tPSA & $0.24(0.11-0.48)$ & $0.18(0.03-0.46)$ & $0.13(0.01-0.65)$ \\
\hline
\end{tabular}

ASAP - atypical small acinar proliferation, PCa - prostate cancer, tPSA - total prostate-specific antigen velocity, fPSA - free prostatespecific antigen velocity, f/tPSA - free to total prostate-specific antigen ratio velocity, PSA-D - prostate-specific antigen density velocity.

Table V. ASAP Scoring System and Risk Table scores and comparison of the two groups

\begin{tabular}{|c|c|c|c|}
\hline Variable & Group 1 & Group 2 & $P$-value \\
\hline Low risk $(n=44)$ & 37 (84.09\%) & 7 (15.91\%) & \\
\hline Intermediate risk $(n=50)$ & $32(64 \%)$ & $18(36 \%)$ & \\
\hline High risk $(n=34)$ & $8(23.52 \%)$ & $26(76.48 \%)$ & \\
\hline $\begin{array}{l}\text { ASAP Scoring System and Risk Table } \\
\text { score }\end{array}$ & $5.75(3-10)$ & $8.23(4-11)$ & $0.001^{*}$ \\
\hline
\end{tabular}

Mann-Whitney $U$ Test, ${ }^{\star} p<0.05$.

the literature, the diagnosis rate of PCa in patients with ASAP on the second biopsy ranges from $39 \%$ to $42 \%[17,18]$. The relationship between ASAP and PCa has been evaluated for many years. Currently, there are no published algorithms for patients with ASAP to avoid unnecessary biopsies. Therefore, a second prostate biopsy is routinely applied to all patients diagnosed with ASAP in accordance with the recommendations in guidelines. There are many studies in the literature focusing on the diagnosis of PCa on second biopsies of patients diagnosed with ASAP. PSA types are analyzed in those studies for their potential predictive values to explain the relationship between ASAP and PCa (Table IV).

Several nomograms were reported to increase detection rates of $\mathrm{PCa}$ in recurrent prostate biopsies. In a study by Sakura et al., a new repeat biopsy nomogram was developed, using patients' age, the f/tPSA rate, and the prostate volume, etc. [19]. However, patients diagnosed with ASAP were not included in that study. Yanke et al. and Moussa et al. reported a nomogram that contained PSA slopes and the history of a highgrade intraepithelial neoplasm or ASAP [20, 21]. A study by Lopez-Corona et al. reported a nomogram using the following parameters: the cumulative number of negative cores obtained, the PSA slope, the history of high grade prostatic intraepithelial neoplasia, and the history of ASAP. Those parameters were associated with repeat biopsy findings [22]. Those studies created nomograms using many parameters; however, such nomo- grams were not found adequate to be routinely recommended in the guidelines. Furthermore, the evaluation of some extra parameters would mean a cost increase. For instance, nomograms require the evaluation of PSA slopes at least three times through new measurements. Moreover, no nomograms were developed specifically for patients with ASAP and such nomograms did not address tPSA level changes between two biopsies. In our study, we have defined and used four parameters that can be measured effectively to decide whether to perform a second prostate biopsy by using the ASS-RT criteria. Compared to other systems developed for such purposes, another important feature of the ASS-RT criteria developed in our study is that these criteria identified patients by risk groups based on the points scored. We consider the risk group classification critical. Using the ASS-RT system, we compared the number of patients in both groups and found that the differences between the two study groups were significant (Table V). A study on the classification of patients with ASAP into low and high risk groups was published in 2005 by Scattoni et al., who found no difference in frequency of getting cancer between the low and high risk groups after repeated biopsies [23]. That study reported no difference between risk groups in the detection of PCa. Contrary to the study by Scattoni et al., the use of the ASAP Scoring System and Risk Table developed in our study increased the predictability of the PCa diagnosis. On the second biopsies in our study, $8 \%$ of the patients 
in the high-risk group had benign prostate pathology, while $50.98 \%(26 / 51)$ of the patients in the high-risk group had PCa. However, Gleason scores of most of the patients with PCa (70.58\%) were $3+3$ and the rate of a clinically significant PCa was $29.42 \%$ in group II. Unfortunately, no prediction parameters for making a diagnosis were identified for patients in the intermediate risk group.

Considering the relationship between ASAP and clinically insignificant PCa, patients with ASAP are not expected to have very high tPSA levels. The mean TPSA level of the cohort in our study ranged from 4.0 to $10.0 \mathrm{ng} / \mathrm{ml}$ and it was in the gray zone. A previous study reported that the rate of $\mathrm{PCa}$ detection was $25.1 \%$ on the first biopsy and that the rate of clinically significant $\mathrm{PCa}$ detection was lower in men with PSA levels of $4.0-10.0 \mathrm{ng} / \mathrm{ml}$ [24]. As mentioned previously, this rate is approximately $40 \%$ across patients diagnosed with ASAP. However, the rate of clinically significant PCa in our study was $11.71 \%$ in all patients with ASAP. Because the rate of diagnosing a clinically significant PCa on the second biopsy is less than expected in patients with ASAP, we think that the best way to prevent high costs and increased morbidity associated with re-biopsies is to identify high-risk patients through ASS-RT.

The main limitation of the study was the retrospective design. The number of patients with missing data precluded us from including more patients in the cohort. Another point that is not a limitation but an improvement factor to be considered could be the evaluation of the time elapsed between two biopsies. This factor was not examined in our study. A thorough examination of the time elapsed between two biopsies and inclusion of this factor in the ASS-RT system developed in this study may increase the effectiveness of the use of the ASS-RT table. The time between two biopsies is perhaps an effective factor in the occurrence of the final pathological diagnosis in patients diagnosed with ASAP.

In conclusion, the risk group classification of patients to be performed using ASS-RT may help identify patients who require a second biopsy. The cut-off value of 7 determined for the ASS-RT score in this study suggests that patients with ASS-RT scores of $\geq 7$ should undergo a second prostate biopsy. Thereby, early diagnosis will be possible for high-risk patients. We think that there may be no need for a second biopsy if the ASS-RT score is < 7, especially for low-risk patients.

\section{Acknowledgments}

The author would like to thank the staff of the Department of Urology in Sultan Abdulhamid Han Education and Research Hospital.

\section{Conflict of interest}

The authors declare no conflict of interest.

\section{References}

1. Siegel RL, Miller KD, Jemal A. Cancer statistics, 2018. CA Cancer J Clin 2018; 68: 7-30.

2. Bostwick DG, Qian J, Frankel K. The incidence of high grade prostatic intraepithelial neoplasia in needle biopsies. J Urol 1995; 154: 1791-4.

3. Cheville JC, Reznicek MJ, Bostwick DG. The focus of "atypical glands, suspicious for malignancy" in prostatic needle biopsy specimens: incidence, histologic features, and clinical follow-up of cases diagnosed in a community practice. Am J Clin Pathol 1997; 108: 633-40.

4. Montironi R, Scattoni V, Mazzucchelli R, Lopez-Bel$\operatorname{tran}$ A, Bostwick DG, Montorsi F. Atypical foci suspicious but not diagnostic of malignancy in prostate needle biopsies (also referred to as "atypical small acinar proliferation suspicious for but not diagnostic of malignancy"). Eur Urol 2006; 50: 666-74.

5. Srirangam V, Rai BP, Abroaf A, et al. Atypical small acinar proliferation and high grade prostatic intraepithelial neoplasia: should we be concerned? An observational cohort study with a minimum follow-up of 3 years. Curr Urol 2017; 10: 199-205.

6. Leone L, Lacetera V, Montironi R, et al. Biopsy follow-up in patients with isolated atypical small acinar proliferation (ASAP) in prostate biopsy. Arch Ital Urol Androl 2014; 86: 332-5.

7. Carroll PR, Parsons JK, Andriole G, et al. Prostate cancer early detection, version 1.2014. Featured updates to the NCCN Guidelines. J Natl Compr Canc Netw 2014; 12: 1211-9.

8. Mottet N, Bellmunt J, Bolla M, et al. EAU-ESTRO-SIOG Guidelines on Prostate Cancer. Part 1: Screening, diagnosis, and local treatment with curative intent. Eur Urol 2017; 71: 618-29.

9. Epstein JI, Herawi M. Prostate needle biopsies containing prostatic intraepithelial neoplasia or atypical foci suspicious for carcinoma: implications for patient care. J Urol 2006; 175: 820-34.

10. Ericson KJ, Wenger HC, Rosen AM, et al. Prostate cancer detection following diagnosis of atypical small acinar proliferation. Can J Urol 2017; 24: 8714-20.

11. Loeb S, Carter HB, Berndt SI, Ricker W, Schaeffer EM. Is repeat prostate biopsy associated with a greater risk of hospitalization? Data from SEER-Medicare. J Urol 2013; 189: 867-70.

12. Loeb S, Vellekoop A, Ahmed HU, et al. Systematic review of complications of prostate biopsy. Eur Urol 2013; 64: 876-92.

13. Quaresima L, Lacetera V, Leone L, et al. The impact of repeated prostate biopsies on sexual function and urinary symptoms in patients with diagnosis of Atypical Small Acinar Proliferation (ASAP): can ecoDoppler reduce side effects? Arch Ital Urol Androl 2014; 86: 356-8.

14. Fandella A. Analysis of costs of transrectal prostate biopsy. Urologia 2011; 78: 288-92.

15. Ynalvez LA, Kosarek CD, Kerr PS, et al. Atypical small acinar proliferation at index prostate biopsy: rethinking the re-biopsy paradigm. Int Urol Nephrol 2018; 50: 1-6.

16. Leone A, Rotker K, Butler C, et al. Atypical small acinar proliferation: repeat biopsy and detection of high grade prostate cancer. Prostate Cancer 2015; 2015: 810159. 
17. Leone A, Gershman B, Rotker K, et al. Atypical small acinar proliferation (ASAP): Is a repeat biopsy necessary ASAP? A multi-institutional review. Prostate Cancer Prostatic Dis 2016; 19: 68-71.

18. Mallen E, Gil P, Sancho C, et al. Atypical small acinar proliferation: review of a series of 64 patients. Scand J Urol Nephrol 2006; 40: 272-5.

19. Sakura M, Kawakami S, Ishioka J, et al. A novel repeat biopsy nomogram based on three-dimensional extended biopsy. Urology 2011; 77: 915-20.

20. Moussa AS, Jones JS, Yu C, Fareed K, Kattan MW. Development and validation of a nomogram for predicting a positive repeat prostate biopsy in patients with a previous negative biopsy session in the era of extended prostate sampling. BJU Int 2010; 106: 1309-14.

21. Yanke BV, Gonen M, Scardino PT, Kattan MW. Validation of a nomogram for predicting positive repeat biopsy for prostate cancer. J Urol 2005; 173: 421-4.

22. Lopez-Corona E, Ohori M, Scardino PT, Reuter VE, Gonen $M$, Kattan MW. A nomogram for predicting a positive repeat prostate biopsy in patients with a previous negative biopsy session. J Urol 2003; 170: 1184-8.

23. Scattoni V, Roscigno M, Freschi M, et al. Atypical small acinar proliferation (ASAP) on extended prostatic biopsies: predictive factors of cancer detection on repeat biopsies. Arch Ital Urol Androl 2005; 77: 31-6.

24. Chen R, Huang Y, Cai X, et al. Age-specific cutoff value for the application of percent free prostate-specific antigen (PSA) in Chinese men with serum PSA levels of 4.0-10.0 ng/ml. PLoS One 2015; 10: e0130308. 